\title{
Lignin nanoparticles modified with tall oil fatty acid for cellulose functionalization
}

\author{
Harri Setälä (D) - Hanna-Leena Alakomi • Arja Paananen • Géza R. Szilvay • \\ Miriam Kellock • Miikka Lievonen • Ville Liljeström • Eva-Lena Hult • \\ Kalle Lintinen $\cdot$ Monika Österberg $\cdot$ Mauri Kostiainen
}

Received: 31 October 2018/Accepted: 25 September 2019/Published online: 3 October 2019

(C) The Author(s) 2019

\begin{abstract}
In this study, tall oil fatty acid ester of softwood kraft lignin (TOFA-L) was used to prepare TOFA lignin nanoparticles (TLNP) in water. The average diameters for two prepared TLNPs in $0.1 \mathrm{mg} /$ $\mathrm{ml}$ concentration were $140 \mathrm{~nm}$ and $160 \mathrm{~nm}$. TLNPs were attached covalently onto modified and unmodified cellulose fibres to form an antimicrobial composite material. The modified cellulose fibres contained reactive allylic double bonds with a degree of substitution of 0.05 . The antimicrobial properties of both TLNPs and TLNP coated fibres (TLNP-C) were studied against Escherichia coli, Staphylococcus aureus and Pseudomonas aeruginosa using silver nanospheres (average size $10 \mathrm{~nm}$ ) and Lignoboost lignin particles with 300 and $400 \mathrm{~nm}$ sizes as references. Antimicrobial activity of the samples was stronger against Gram-positive $S$. aureus cells than against Gram-negative target microbes $E$. coli and $P$. aeruginosa.
\end{abstract}

Keywords Lignin $\cdot$ Nanoparticles $\cdot$ Cellulose $\cdot$ Fatty acid · Allylation

H. Setälä $(\bowtie) \cdot$ H.-L. Alakomi · A. Paananen ·

G. R. Szilvay · M. Kellock · E.-L. Hult

Teknologian Tutkimuskeskus VTT Oy, Espoo, Finland

e-mail: harri.setala@vtt.fi

M. Lievonen · V. Liljeström · K. Lintinen ·

M. Österberg · M. Kostiainen

Aalto University, Espoo, Finland

\section{Introduction}

Lignin is an aromatic polyphenol and one of the most abundant biopolymers along with cellulose and hemicelluloses in plants and especially in wood species. The native lignin contains many functional groups such as phenolic and aliphatic hydroxyl groups, methoxyl groups, carbonyl groups (- $\mathrm{CHO}$ and $\mathrm{COOH}$ ) that have an impact on its reactivity and other chemical properties. Technical kraft and lignosulfonate lignins are mainly produced in large quantities as a side-product from kraft pulping processes and the sulfite processes, respectively. The sulfur content of kraft lignins is low, typically less than 1-2\%, which increases the potential for versatile material applications of kraft lignin. The chemistry and structure of lignins, the effect of pulping processes on its structure and properties, and valorization of lignins for different kind of novel products and applications have been discussed in several recent reviews. In many cases, lignin modification is necessary for improved properties, and a prerequisite for use in applications such as composites, adhesives, resins, or polyurethane based materials (Ralph et al. 2004; Duval and Lawoko 2014; Laurichesse and Avérous 2014; Crestini et al. 2017; Spiridon 2018).

Lignin and its derivatives, such as lignin nanoparticles (LNP), have been shown to exhibit antioxidative, UV protecting and/or antimicrobial and other bioactive properties (Dong et al. 2011; Yearla and Padmasree 2016; Figueiredo et al. 2017; Farooq et al. 
2019; Figueirodo et al. 2018). Lignin has also been observed to be a necessary reducing component when silver nanoparticles are prepared onto the surface of regenerated cellulose membranes ( $\mathrm{Hu}$ and Hsieh 2015). Kraft lignin has been used as a starting material when silica/lignin hybrid materials, modified with nanosilver, were obtained and studied as antimicrobial materials (Klapiszewski et al. 2015). LNPs have also been used as templates to prepare polyacrylamidegrafted LNPs for emulsion purposes as biosurfactants (Silmore et al. 2016) and nanocomposites grafted with poly (methyl methacrylate) (Yang et al. 2018). Lignin nanoparticles (LNP) or colloidal lignin particles (CLPs) have recently attained considerable interest for many kind of purposes such as biomedical applications and the most common methods for preparation of LNPs were described, for example, by Zhao et al. (2016) or Figueirodo et al. (2018). Additionally, some techno-economical assessments have been done for the production of LNPs in a larger scale (Ashok et al. 2018). One popular method is based on dissolving lignin in an organic solvent or mixture of solvents and the subsequent spontaneous formation of spherical particles in the range 100-300 nm upon precipitation in excess of water acting as an antisolvent (Lievonen et al. 2016). This approach has recently been shown to be scalable (Lintinen et al. 2018; Ashok et al. 2018).

Lignin as such is not highly reactive in free-radical reactions such as graft polymerizations or coupling reactions, for example, due to the residual double bonds of lignins that are 1,2-subtituted and not reactive towards free-radical attack (Doherty et al. 2011). Additionally, the reactivity in free-radical reactions with unsaturated polymers is limited due to the ability of phenolic hydroxyl in lignin to act as radical scavengers (Lu et al. 1998; Tagami et al. 2019). More generally, the radical polymerization of lignins has been reported to have four main disadvantages: (1) There is less control of the grafting reaction; (2) the grafting efficiency can be reduced by the homopolymerization of the vinylic monomers; (3) the radicals are resonance-stabilized on different positions on the aromatic ring of the lignin, thus it is not possible to know exactly where the grafting takes place on the lignin structure; and (4) coupling reactions between the lignin radicals can also occur and this competes with the grafting (Duval and Lawoko 2014;
Figueirodo et al. 2018). However, LNPs as such have also been used for grafting reactions (Yang et al. 2018).

Crude tall oil consists typically of fatty acids and rosin acids. Tall oil also contains $6.5-20 \mathrm{wt} \%$ unsaponified (neutral) compounds (Aro and Fatehi 2017). The tall oil fatty acid fraction (TOFA) can be produced by using distillation to remove rosin acids from the crude tall oil (Lindberg 2003). The TOFA and fatty acid esters of lignin have been synthetized to produce novel lignin-based products, for example, for coating of paper boards and to improve board properties (Hult et al. 2013), or to improve compatibility of lignin with polystyrene (Pawar et al. 2016). TOFA compounds contain reactive double bonds that can be utilized for grafting purposes (Uschanov et al. 2008; Rämänen and Maunu 2014; Wang et al. 2018). Lignin esters of maleic acid or trans-2-butenoic acid (crotonate) derivatives have also been used for improving the reactivity of lignin towards cross-linking and grafting reactions in thermal processes (Hu et al. 2014; Luo et al. 2018). The esterification and activation with 2-bromoisobutyryl bromide is also used to increase reactivity of lignin and selectivity for the atom transfer radical polymerization (ATRP) (Li et al. 2015).

In a similar manner, cellulose fibres or other polysaccharides such as xylan can be modified, for example, by etherification with allyl glycidyl ether to reactive cellulose derivatives for grafting purposes (Pohjanlehto et al. 2011; Qi et al. 2012; Vehviläinen et al. 2015). The grafting efficiency of allylated derivatives have been observed to be higher compared with unmodified ones, for instance, when unmodified and allylated starches were compared in the grafting with acrylic acid (Zhu et al. 2009).

The objective of this work was to investigate if lignin nanoparticles with added value could be prepared from TOFA-lignin. The hypothesis was that TOFA would bring potential reactivity to the nanoparticles enabling due to the double bonds of TOFA, for example, chemical conjugation of lignin onto cellulose in water suspension. In this work we first modified lignin with tall oil fatty acid to yield a TOFA ester of lignin (TOFA-L). TOFA-L was dissolved in tetrahydrofuran and then this solution was used for the preparation of TOFA-lignin nanoparticles (TLNP) using the anti-solvent precipitation method. The TLNPs were linked covalently onto unmodified and modified cellulose fibres, which were then coated onto 
a filter paper support. The antimicrobial properties of TLNPs and TLNP modified cellulose fibres on filter paper support were finally studied.

\section{Experimental}

\section{Materials}

Tall oil fatty acid (TOFA) was a received from Forchem (Rauma, Finland).). According to the product data sheet of the suppliers (product FOR5, www. forchem.com/tall_oil_products), it contains 3.5\% saturated fatty acids (C16 palmitic acid 1.2\%, C18 stearic acid $1.5 \%, \mathrm{C} 20$ arachidic acid $0.8 \%$ ) and $86.3 \%$ unsaturated fatty acids (C18:1 oleic acid 24.9\%, C18:2 linoleic acid 52.4\%, C18:3 linolenic acid 9.0\%). Total content of free carboxylic acids is $92 \%$, rosin acids $5 \%$, and unsaponifiables $3 \%$. The weight-average molecular weight of TOFA was calculated to be $280.5 \mathrm{~g} / \mathrm{mol}$. Kraft process lignin purified with the Lignoboost process was provided by StoraEnso $\left(\mathrm{M}_{\mathrm{n}}\right.$ $2289, \mathrm{M}_{\mathrm{w}}$ 4450, polydispersity 1.9). Allyl glycidyl ether (AGE, purity 99\%) and other chemicals were purchased from Sigma-Aldrich. The cellulosic starting material was a medium viscosity dissolving grade softwood (TCF) pulp produced by Domsjö Cellulose Fabriker AB, Sweden.

\section{Synthesis of TOFA lignin esters}

Synthesis and characterization of the TOFA functionalized lignin ester samples have been described in the previous article (Hult et al. 2013). First, TOFA acid chloride was synthetized using thionyl chloride. TOFA acid chloride was then reacted with lignin in dry dimethylformamide using triethyl amine as a catalyst to yield the TOFA lignin esters, TOFA -L-50 and TOFA-L-100. TOFA lignin ester and Lignoboost lignin samples were phosphitylated according to literature method (Granata and Argyropoulos 1995; Hult et al. 2013). Freshly prepared samples were measured with ${ }^{31} \mathrm{P}$ NMR immediately after preparation at room temperature. Spectra was measured on a Varian Mercury-VX300 MHz and compiled from 512 transients using $5 \mathrm{~s}$ pulse delay for 90 pulse. The chemical shift scale was calibrated on the signal for phosphitylated water (132.2 ppm). One measurement per sample was carried out. According to the ${ }^{31} \mathrm{P}$ NMR spectroscopic method $88 \%$ and $98 \%$ of the aliphatic and phenolic hydroxyl groups in the Lignoboost lignin have esterified with TOFA yielding the products TOFA-L-50 and TOFA-L-100, respectively, see Table 1. The yields of both TOFA lignin esters were similar to the previously published results (Hult et al. (2013), approximately $70 \%$.

\section{Preparation of lignin nanoparticles}

Formation of TOFA-lignin nanoparticles (TLNP50 and TLNP100) were prepared using THF as a solvent. $0.48 \mathrm{~g}$ of TOFA-L-50 or TOFA-L-100 was dissolved in $360 \mathrm{ml}$ of THF. $480 \mathrm{~g}$ of Milli Q water was slowly (30 min) added to the solution under stirring at room temperature. Thereafter, the main part of THF was evaporated using rotavapor, and finally the TLNP suspension was dialysed using a membrane with cutoff $3500 \mathrm{Da}$. The final concentration of lignin nanoparticles in water suspension was $1 \mathrm{mg} / \mathrm{ml}$. The overall yield of TLNPs was approximately $100 \%$. The unconjugated Lignoboost lignin nanoparticles with sizes $300 \mathrm{~nm}$ (ML10) and $400 \mathrm{~nm}$ (ML11) were prepared in similar way but without evaporation step of THF. In this method lignin nanoparticles were formed during the slow dialysis process as described earlier (Lievonen et al. 2016).

\section{Characterization of nanoparticles in dispersions}

The mean particle size and zeta potential (by Smoluchowski model) of the lignin samples TLNP50, TLNP100, ML10 and ML11 were measured using a Malvern zetasizer-instrument (UK) from three independent measurements. The dispersion stability was evaluated by re-measuring the particle size and zeta potential at different times (up to 11 months). The zeta potential of the dispersions was also determined at different $\mathrm{pH}$ values, ranging from 2 to $7 \mathrm{pH}$ was adjusted by $\mathrm{HCl}$ or $\mathrm{NaOH}$ solutions).

Transmission electron microscopy

Transmission electron microscopy (TEM) was performed on a FEI Tecnai 12 (USA) operating at 
Table 1 Amounts of different hydroxyl group species $(\mathrm{mmol} / \mathrm{g})$ in lignin samples. It was assumed that the lignin content of the sample was $100 \%$

\begin{tabular}{llllllll}
\hline Sample & Aliphatic OH & Carboxylic acid & Condensed + syringyl & Guaiacyl & $\begin{array}{c}p-\mathrm{OH}- \\
\text { phenyl }\end{array}$ & Phenolic OH & Total OH \\
\hline Lignoboost lignin & 1.70 & 0.40 & 2.00 & 2.30 & 0.20 & 4.50 & 6.60 \\
TOFA-L-50 & 0.29 & 0.12 & 0.20 & 0.18 & 0.00 & 0.38 \\
TOFA-L-100 & 0.00 & 0.15 & 0.00 & 0.00 & 0.00 & 0.00 \\
\hline
\end{tabular}

$120 \mathrm{kV}$. Water dispersions were applied onto a carbon film support grid, incubated for 2 min and excess water was removed by blotting the side of the grid onto a filter paper. Imaging was done in bright-field mode with slight under focus.

Preparation of cellulose and allylated cellulose fibres

The mechanical and enzymatic treatment and allylation were performed according to the published procedure by Vehviläinen et al. 2015. The dry Domsjö cellulose sheets were first shredded mechanically for $5 \mathrm{~h}$ using a Baker Perkins shredding machine and thereafter treated with enzyme preparation at $\mathrm{pH} 5$, $50{ }^{\circ} \mathrm{C}$ for $2 \mathrm{~h}$. The dry matter content after this treatment was $23.6 \%$ of cellulose. Wet enzyme-treated pulp $(850 \mathrm{~g})$ containing $200 \mathrm{~g}$ of cellulose $(1.24 \mathrm{~mol}$ of anhydroglucose units, AGU) was weighed and added into a reaction flask with $1440 \mathrm{~mL}$ of water and with $1730 \mathrm{~mL}$ of $90 \%$ aqueous tert-butanol. $240 \mathrm{ml}$ of $10 \mathrm{M} \mathrm{NaOH}$ was added to adjust the molarity of $\mathrm{NaOH}$ to $1 \mathrm{M}$ in respect of the total amount of water in the reaction mixture. The $\mathrm{NaOH} / \mathrm{AGU}$ ratio was 1.9 . The reaction mixture was stirred first for $2 \mathrm{~h}$ at $65{ }^{\circ} \mathrm{C}$, cooled down to room temperature and stirred overnight for activation with $\mathrm{NaOH}$. The reaction mixture was then heated to $45^{\circ} \mathrm{C}$, allyl glycidyl ether $(187 \mathrm{~mL})$ was added, and the reaction mixture was stirred again overnight at $45{ }^{\circ} \mathrm{C}$. The molar ratio of AGE/AGU was 1.27. The degree of substitution $\left(\mathrm{DS}_{\mathrm{A}}\right)$ of the 3-allyloxy-2-hydroxypropyl substituted enzyme-treated pulp was characterized using a solid state ${ }^{13} \mathrm{C} C P / M A S$ NMR spectroscopy. The $\mathrm{DS}_{\mathrm{A}}$ was 0.05 . Dry matter content of allylated cellulose pulp was $17.6 \%$.
Functionalization of cellulose and allylated cellulose fibres with TLNPs

$250 \mathrm{ml}$ of TLNP50 and TLNP100 nanoparticle suspensions $(0.25 \mathrm{~g}$ of TNLPs in $250 \mathrm{ml})$ were used for each functionalization batch and added into a $500 \mathrm{ml}$ reactor. $5.0 \mathrm{~g}$ of modified, allylated cellulose fibres $(0.88 \mathrm{~g}$ of $\mathrm{AC})$ or $3.7 \mathrm{~g}$ of unmodified cellulose $(0.88 \mathrm{~g}$ of C) fibres was added with stirring $(350 \mathrm{rpm})$. The reaction mixture was heated up to $+65{ }^{\circ} \mathrm{C}$. $0.25 \mathrm{~g}$ of ammonium persulfate (APS) was used as the radical initiator and added in $5 \mathrm{ml}$ of water. The reaction mixture was stirred for $18 \mathrm{~h}$ at $+65^{\circ} \mathrm{C}$. The reaction mixture was cooled down to $+22{ }^{\circ} \mathrm{C}$. The cellulose fibres with TLNPs (TLNP-50-AC, TLNP100-AC, and TLNP-100-C) were filtrated onto a filter paper $(\phi 125 \mathrm{~mm}, \mathrm{~S} \& \mathrm{~S} 595$, medium fast with a pore size 4-7 $\mu \mathrm{m}$ ) using a Büchner funnel and washed several times with deionized water to remove salts and TLNPs that were not attached onto cellulose fibres. The TLNP-50-AC, TLNP-100-AC, TLNP100-C samples were dried on a filter paper at RT and weighed. The yields were calculated based on the amounts of used TLNPs and cellulose fibres compared with the weighed amounts of TLNP and cellulose fibres on a filter paper. The yields were $92 \%$ of TLNP-50-AC, 95\% of TNLP-100-AC, and 91\% of TLNP-100-C. Only a small amount of the starting materials, either TLNPs or cellulose fibres, were lost.

Reference filter paper sheets with allylated $(5.0 \mathrm{~g})$ or unmodified $(3.7 \mathrm{~g})$ cellulose fibres without any TLNPs were prepared in similar manner as described above by treating the sheets only with APS in $250 \mathrm{ml}$ of deionized water instead of $250 \mathrm{ml}$ of TLNP suspensions. TLNP100 suspension without addition of cellulose fibres and APS treatment was also filtered through the filter paper. 
Scanning electron microscopy

Scanning electron microscopy (SEM) was performed on JEOL JSM-7500FA analytical field-emission scanning electron microscope. The images were taken at $5 \mathrm{kV}$ voltage. The freestanding films were attached on the SEM sample holders with carbon tape and the samples were metal coated by gold plasma sputtering at $30 \mathrm{~mA}$ for $2 \mathrm{~min}$.

\section{Antimicrobial activity tests}

The antimicrobial activity (antibacterial and antifungal) of TOFA-lignin nanoparticle solutions (TLNP50 and TLNP100) was analysed with modified CLSI M100-S19 method in Mueller-Hinton II broth. Silver nanospheres (Sigma-Aldrich 795925, average size $10 \mathrm{~nm}$ ) and ML10 and ML11 particles were used as reference. Escherichia coli VTT E-94564, Staphylococcus aureus VTT E-70045 and Pseudomonas aeruginosa VTT E-96726 were obtained from VTT Culture Collection and used as the target microbes. Briefly, two-fold dilutions from the test samples were prepared into broth and mixed with an inoculum $\left(10^{6}\right.$ cells/ml) prepared from overnight at $37{ }^{\circ} \mathrm{C}$ grown bacterial cells. Growth of the samples in microwell system at $37^{\circ} \mathrm{C}$ was monitored with automated turbidometer, Bioscreen $\mathrm{C}^{\mathrm{TM}}$ (Thermo Scientific, Finland) and Research Express software (Transgalactic Ltd, Finland) for $48 \mathrm{~h}$. Growth inhibition \% values were calculated from the growth curves (Alakomi et al. 2006).

The antimicrobial activity of TLNP100-modified cellulose films was examined against $S$. aureus VTT E-70045 and E. coli VTT E-94564 by applying target cells directly on the sample surface. Filter paper, unmodified cellulose and a commercial silver blaster were used as reference. Briefly, overnight in Trypticase soy broth grown cells were diluted in peptone saline and 105 cells applied on test pieces (diameter $12 \mathrm{~mm}$ ). Samples were incubated at $37^{\circ} \mathrm{C}$ for $1 \mathrm{~h}$ and viability of the cells analyzed with plate count technique on plate count agar.

\section{Results and discussion}

Characterization of TOFA lignin nanoparticles

Preparation of TOFA conjugated lignin was performed as described by Hult et al. 2013. The results of ${ }^{31} \mathrm{P}$ NMR analyses for lignins and TOFA lignins are presented in Table 1 . The total hydroxyl group content of Lignoboost lignin was $6.60 \mathrm{mmol} / \mathrm{g}$. The results show that nearly all of the aliphatic and phenolic hydroxyl groups of lignin have reacted, forming TOFA lignin esters: TOFA-L-50 with yield $88 \%$ and TOFA-L-100 with the yield 98\%. These yields are very well in line with the results published by Hult et al. 2013, where the yields were $75 \%$ and $100 \%$, respectively.

TOFA lignin nanoparticles were prepared using a similar protocol as described previously for kraft lignin using THF and solvent exchange via dialysis (Lievonen et al. 2016). The main difference in our approach was that the solvent exchange from THF to water was made first by adding water slowly to TOFA lignin dissolved in THF under stirring and evaporating the solvent using a rotavapor. Dialysis was done as a final step to remove the residual THF. The TEM results (Fig. 1) show that spherical nanoparticles, less than $200 \mathrm{~nm}$ in diameter can be prepared from TOFA lignin by this approach. The average diameter for ready-made nanoparticles in $0.1 \mathrm{mg} / \mathrm{ml}$ concentration was $140 \pm 42 \mathrm{~nm}$ and $160 \pm 39 \mathrm{~nm}$ for TLNP50 and TLNP100, respectively. The average diameter is approximately half of the size reported by Lievonen et al. 2016 and most likely originates from a faster solvent exchange procedure. This conclusion is further supported by more recent finding regarding LNP preparation (Leskinen et al. 2017, Lintinen et al. 2018).

As shown in Table 1, the most of the aliphatic and phenolic hydroxyl groups of lignin have reacted with TOFA. When lignin nanoparticles are dispersed in water the underivatized phenolic hydroxyl and carboxyl groups provide the particles a surface charge, which can stabilize the nanoparticle dispersion by electrostatical interactions. Typically, the amount of underivatized carboxylic acid groups increased from the original values $0.3-0.4$ up to $0.5-1.0 \mathrm{mmol} / \mathrm{g}$ for TOFA lignin esters (Hult et al. 2013). The zeta potential values were very similar for both TLNPs, being approximately $-30 \mathrm{mV}$ (Fig. 2). This can be 


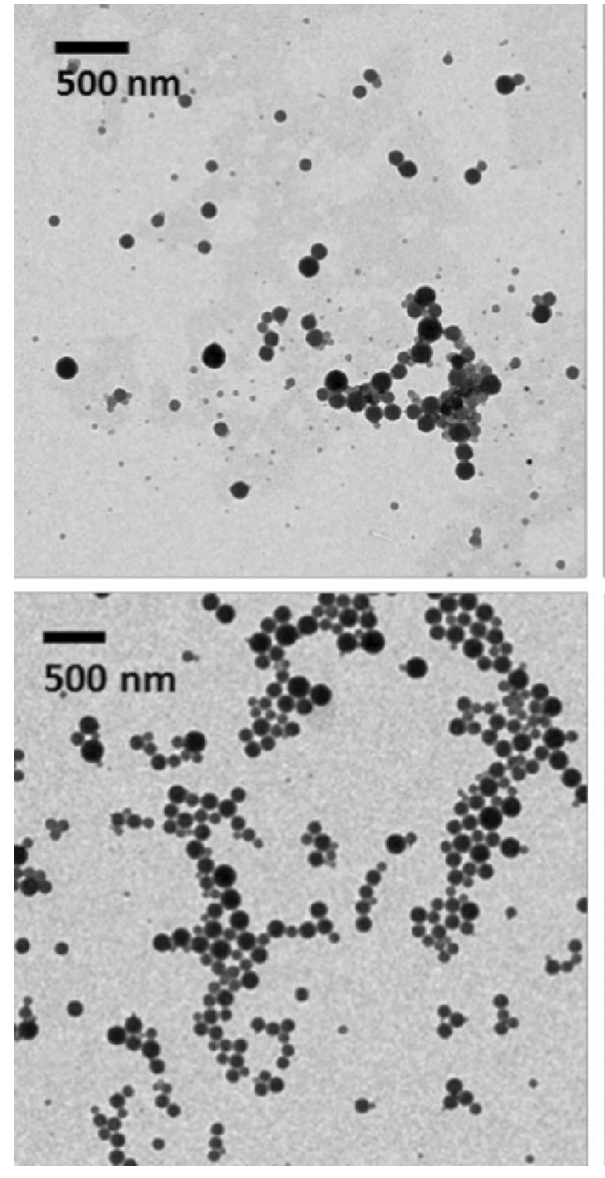

Fig. 1 TEM images of TLNP50 (top) and TLNP100 (bottom)

explained by the similar amount of carboxylic acid groups (Table 1) in both TLNPs. On the other hand, the zeta potential value is only a half of the corresponding value $(-60 \mathrm{mV})$ for lignin nanoparticles produced from the same lignin raw material, but without TOFA-conjugation. In aqueous dispersion, the surface charge originates mainly from deprotonated carboxylic acid groups, but at high enough $\mathrm{pH}$ also from the free non-derivatized phenolic hydroxyl groups at the particle surface. The amount of free carboxylic groups is clearly lower in TLNPs as compared to unmodified LNPs (Table 1) explaining the lower zeta potential. The surface charge is still high enough to prevent aggregation: both TLNPs are stable colloids (Fig. 2.). However, the stability of TLNPs may also be partly due to steric repulsion between TOFA - chains attached to the LNPs. We monitored the size and zeta potential of both TLNPs for over 300 days after preparation (stored at $+4{ }^{\circ} \mathrm{C}$ )
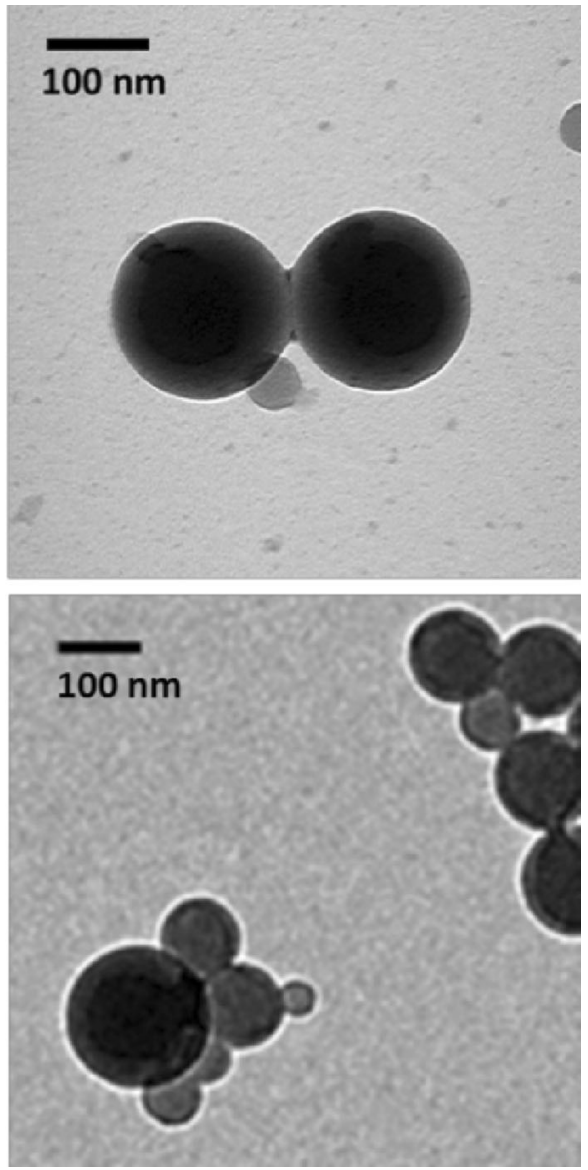

and the values remained at the same level, indicating very good colloidal stability of the particle dispersion. Some variation is observed, but since it is not systematic, i.e. we do not see a systematic increase in particle size or decrease in charge with time, we conclude that these variations are not significant.

Antimicrobial properties of TOFA lignin nanoparticles

Antimicrobial activity of silver nanoparticles (AgNP) have been reported and mechanisms of antimicrobial activity linked to interaction of AgNPs with bacterial cell membranes (Hajipour et al. 2012; Romero-Urbina et al. 2015). Romero-Urbina et al. (2015) observed in their experiments that positively charged silver nanoparticles (average size $10 \mathrm{~nm}$ ) induced thinning and permeabilization of the Gram-positive $S$. aureus cell wall, destabilization of the peptidoglycan layer, 

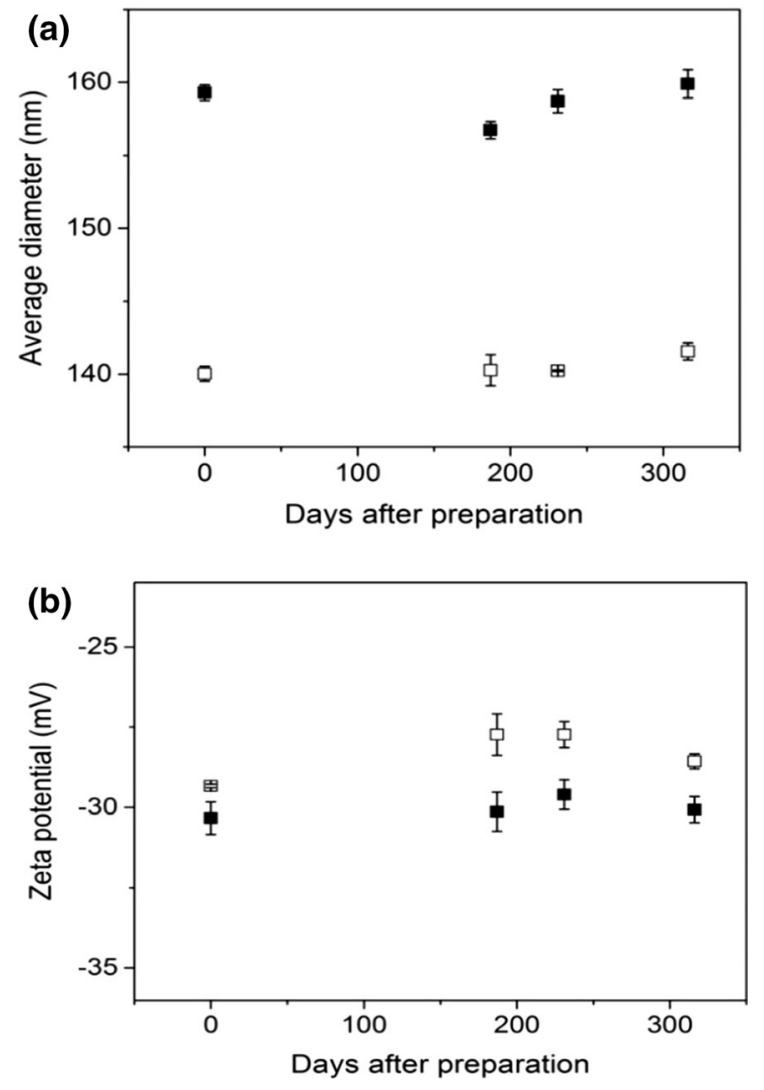

Fig. 2 Stability of lignin nanoparticles, TLNP50 (open symbols) and TLNP100 (closed symbols). a average hydrodynamic diameter and $\mathbf{b}$ zeta potential in pure water as a function of time and subsequent leakage of intracellular content, causing bacterial cell lysis. In our experiments the size of the examined TOFA lignin nanoparticles was around $160 \mathrm{~nm}$ which indicates different mode of action. TLNP50 and TLNP100 samples at $0.5 \mathrm{mg} / \mathrm{ml}$ concentration had antimicrobial activity, and growth inhibition \% against $S$. aureus E-70045 was $51 \pm 21 \%$ and $31 \pm 6 \%$, respectively (Fig. 3, Table 2). Antimicrobial activity of ML10 and ML11 samples (references) against S. aureus was weaker than with the TOFA lignin nanoparticles. Antimicrobial activity of the samples was stronger against Grampositive $S$. aureus cells than against Gram-negative target microbes E. coli and P. aeruginosa (Table 2).

Treatment of cellulose fibres with TOFA lignin nanoparticles

The coupling of TLNPs onto allylated cellulose fibres happens as a radical initiated reaction between reactive double bonds of TLNPs and allyl groups of cellulose fibres as presented in Fig. 4. The reactivity of different unsaturated fatty acids and TOFA based materials in grafting reactions, for example, with acrylic monomers has been studied, when so-called alkyd-acrylic copolymers and hybrid material have been prepared. It has been shown that both the isolated double bonds of oleic acid and the double allylic sites of linoleic and linolenic acids are reactive in free
Fig. 3 Example of the bacteriostatic activity of the nanoparticles against Staplylococcus aureus VTT E-70045. Growth was monitored with automated turbidometer Bioscreen during $48 \mathrm{~h}$ experiment in liquid culture

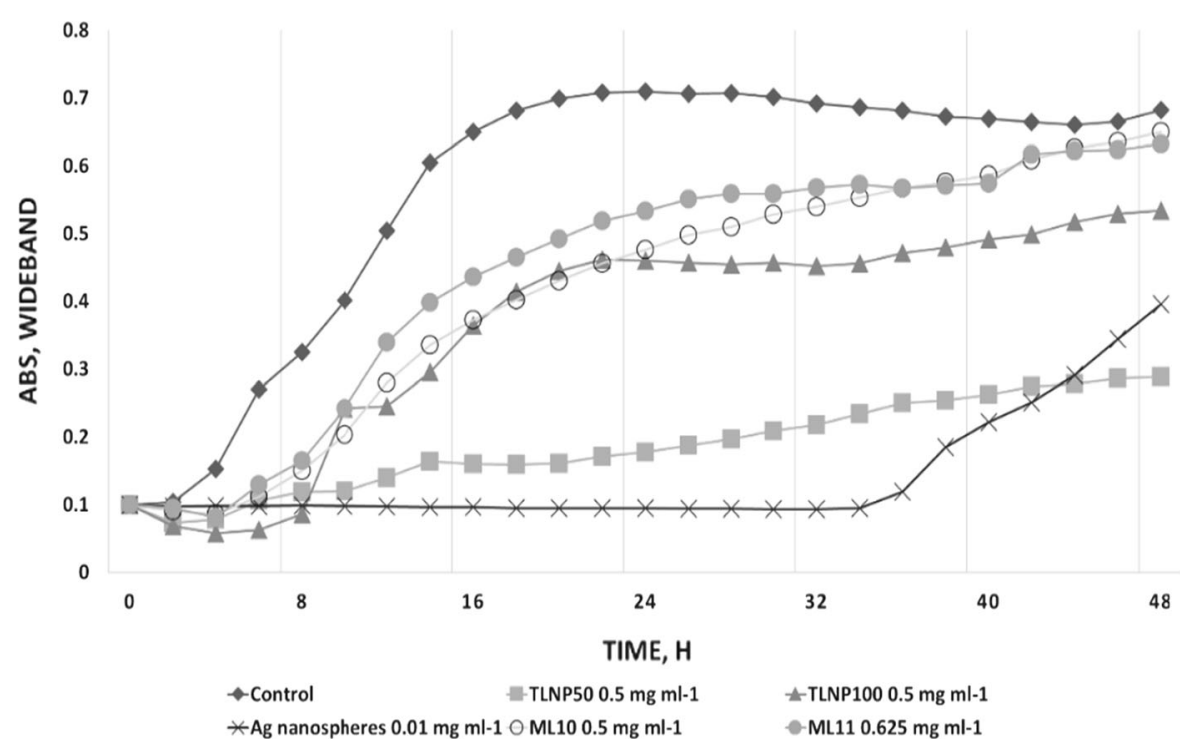


Table 2 Summary of the antimicrobial activity of the samples as growth inhibition (\%) after $48 \mathrm{~h}$ in sample solutions. Test concentrations were 0.50 and $0.25 \mathrm{mg} / \mathrm{ml}$

\begin{tabular}{|c|c|c|c|c|c|c|}
\hline \multirow[t]{2}{*}{ Sample } & \multicolumn{2}{|c|}{$\begin{array}{l}\text { Staphylococcus aureus } \\
\text { VTT E-70045 }\end{array}$} & \multicolumn{2}{|c|}{$\begin{array}{l}\text { Escherichia coli } \\
\text { VTT E-945678 }\end{array}$} & \multicolumn{2}{|c|}{$\begin{array}{l}\text { Pseudomonas auruginos } \\
\text { VTT E-96726 }\end{array}$} \\
\hline & 0.50 & 0.25 & 0.50 & 0.25 & 0.50 & 0.25 \\
\hline TLNP50 (140 nm) & $51 \pm 21$ & $15 \pm 1$ & $25 \pm 10$ & $12 \pm 2$ & $21 \pm 4$ & $13 \pm 6$ \\
\hline TLNP100 $(160 \mathrm{~nm})$ & $31 \pm 6$ & $17 \pm 9$ & $39 \pm 24$ & $15 \pm 1$ & $12 \pm 1$ & $3 \pm 1$ \\
\hline ML10 (300 nm) & $23 \pm 1$ & $10 \pm 3$ & $36 \pm 5$ & $14 \pm 3$ & $26 \pm 1$ & $13 \pm 3$ \\
\hline $\operatorname{ML}_{11}^{\mathrm{a}}(500 \mathrm{~nm})$ & $25 \pm 4$ & $13 \pm 1$ & $12 \pm 4$ & $2 \pm 3$ & $15 \pm 2$ & $6 \pm 2$ \\
\hline $\operatorname{AgNP}^{b}(10 \mathrm{~nm})$ & $64 \pm 16$ & $28 \pm 3$ & $97 \pm 1$ & $91 \pm 1$ & $97 \pm 0$ & $93 \pm 2$ \\
\hline
\end{tabular}

${ }^{\mathrm{a}}$ Test concentrations with ML11 0.625 and $0.3125 \mathrm{mg} \mathrm{ml}^{-1}$

b Test concentrations with AgNP 0.01 and $0.005 \mathrm{mg} \mathrm{ml}^{-1}$

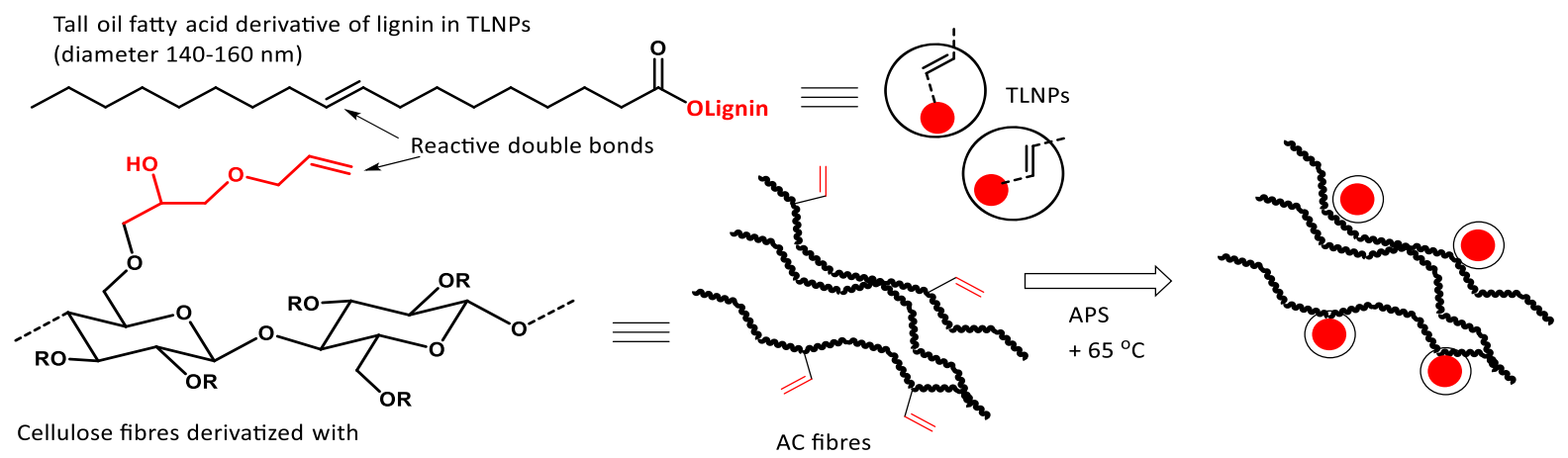

3-allyloxy-2-hydroxypropyl substituents (AC fibres)

Degree of subsitution $\mathrm{DS}_{\text {allyl }} 0.05$

Fig. 4 Scheme of the coupling reaction between reactive double bonds in TLNPs and modified cellulose fibres

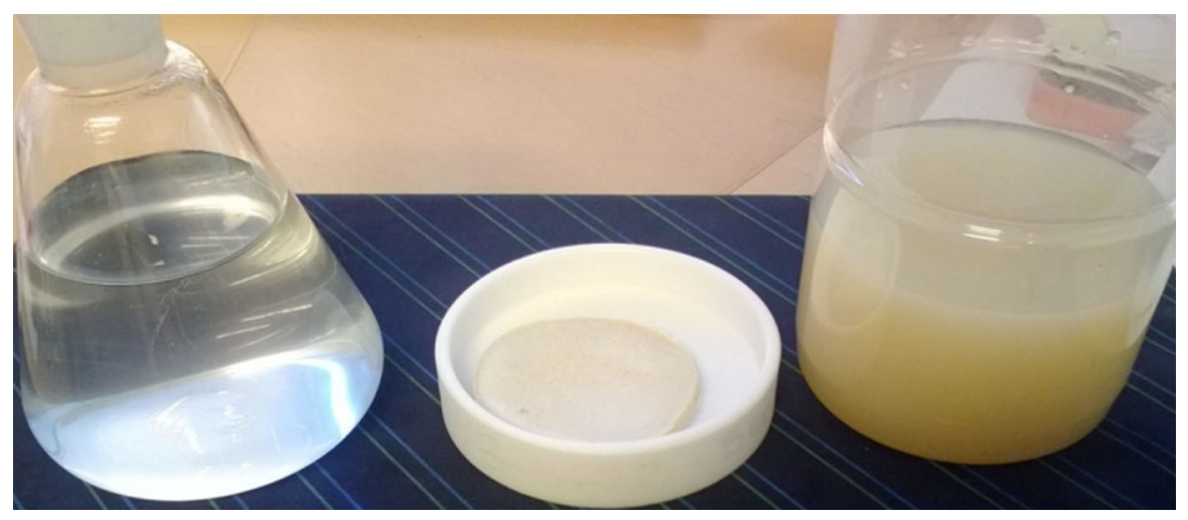

Fig. 5 The suspension of TLNP50 after reaction with allylated cellulose fibres (left), the filtrated suspension on a filter paper sheet (middle), and the clear filtrate of suspension (right)

radical grafting reactions with monomers such as methyl methacrylate or butyl acrylate (Uschanov et al. 2008; Wang et al. 2018).
The reaction was very effective between both TLNPs and allylated cellulose fibres with yields over $90 \%$ and the filtrates were bright in every case indicating that practically all the cellulose fibres 
Fig. 6 SEM images of functionalized cellulose surfaces. TLNP100 particles on unmodified cellulose (left) and on allylated cellulose (right). The SEM images on top row are control surfaces of unmodified cellulose. The middle and bottom rows show samples after TLNP attachment at low and high magnification respectively. The scale bars are shown in the images. The SEM images on bottom rows show clearly that TLNPs have reacted more uniformly with allylated cellulose fibres (right)
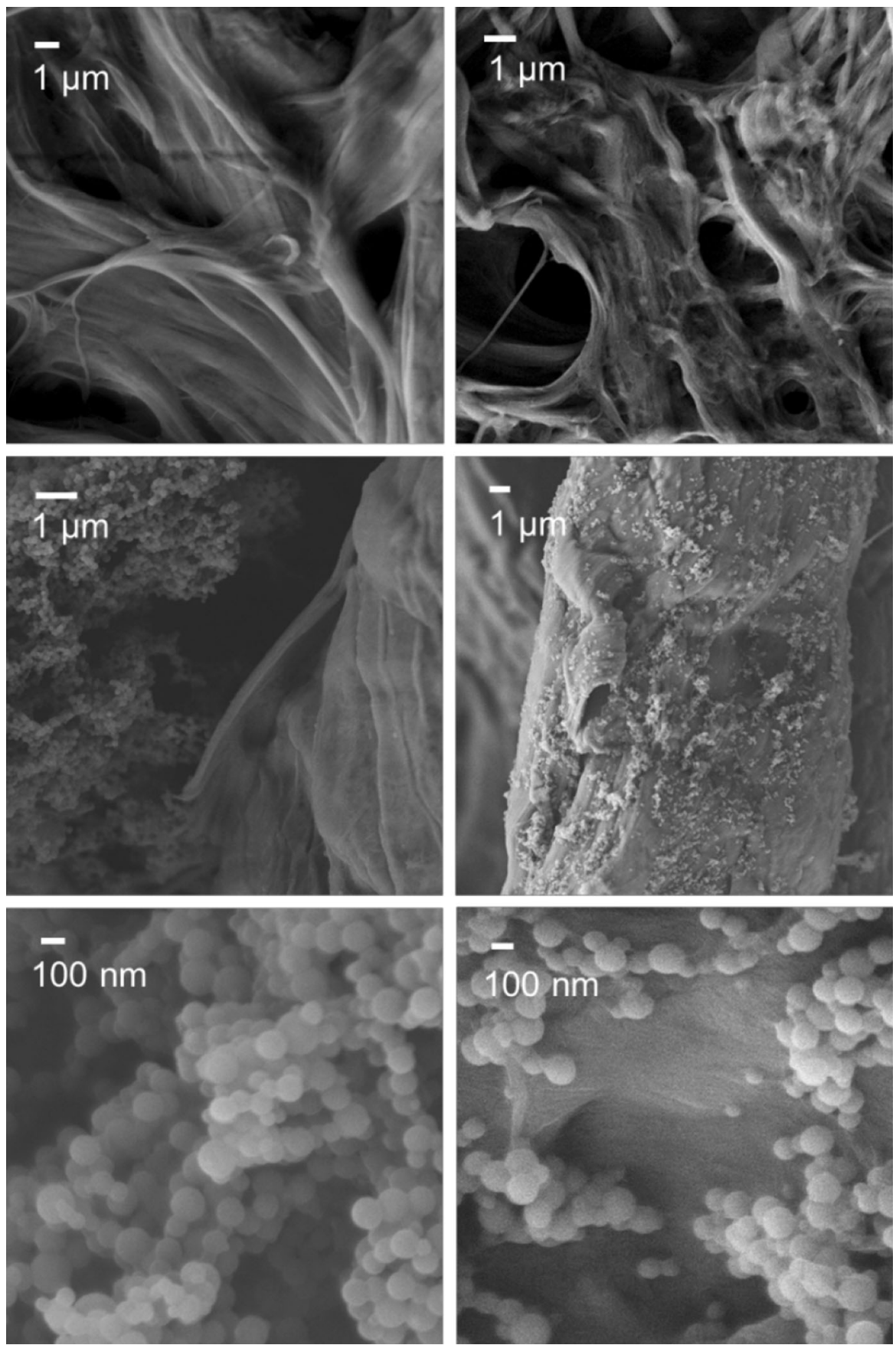

coated with TLNPs were collected onto the filter paper sheets as illustrated in the Fig. 5. The dark brown colour of unbound TOFA lignin ester was not observed in the filtrate. The unmodified cellulose fibres can also react with TLNPs in a similar way as observed in the case of starch that doesn't contain any double bonds ( $\mathrm{Li}$ et al. 2011). The distribution of
TLNPs onto the unmodified cellulose fibres was different from the distribution of TLNPs on the modified allylated cellulose fibres, which can be observed in the SEM images presented in Fig. 6. The TLNPs have distributed clearly more evenly onto the allylated fibres, whereas on unmodified fibres the TLNPs form larger clusters. The reaction of TLNPs 
Table 3 Survival of target microbes (colony forming units per sample) on tested sample surfaces after 30 min contact time

\begin{tabular}{lll}
\hline Sample & $\begin{array}{l}\text { Staphylococcus aureus } \\
\text { VTT E-70045 }\end{array}$ & $\begin{array}{l}\text { Escherichia coli } \\
\text { VTT E-94564 }\end{array}$ \\
\hline Filter paper & $5 \times 10^{3}$ & $1.0 \times 10^{4}$ \\
Unmodified cellulose (APS) & $2.0 \times 10^{4}$ & $5.0 \times 10^{3}$ \\
Silver blaster & $2.0 \times 10^{4}$ & $1.0 \times 10^{4}$ \\
Allylated cellulose (APS) & $<10$ & $<10$ \\
TLNP100 on unmodified cellulose (APS) & $<10$ & $<10$ \\
TLNP100 on allylated cellulose (APS) & $<10$ & $<10$ \\
\hline
\end{tabular}

takes place also with other TLNPs particles which is similar to homopolymerization and it reduces grafting efficiency, especially, onto the unmodified cellulose fibres. This observation indicates that the allyl groups of modified cellulose fibres react with double bonds of TLNPs causing even distribution of particles on the surface. However, without the grafted allyl groups, the TLNPs react more easily with themselves forming clusters. Zhu et al. (2009) have observed a similar effect when they compared the grafting efficiencies of unmodified starch and allyl modified starch with acrylic momoners. The grafting efficiency (63-74\%) was much higher with the allyl modified starch compared to the unmodified starch 53\%). The grafting efficiency depended on the $\mathrm{DS}_{\mathrm{A}}$ varying from 0.005 up to 0.068 . Already a very low DS improved the grafting efficiency. Li et al. (2011) have also observed similar behaviour with acrylated starch with DS 0.005-0.036 yielding higher grafting efficiency $66-81 \%$ than with unmodified starch 57\%.

Brown or brownish colour of lignin or TNLPs was not detected in the filtrate when TLNP-coated filter paper sheets were washed with 50\% aqueous acetone, which indicates covalent bonding between TLNPs and cellulose fibres. Otherwise the brownish colour should be observed due to a rather high solubility of lignins even in 50\% aqueous acetone (Domínguez-Robles et al. 2018). Brown colour due to the solubilized lignin was detected only when samples were treated with $1 \mathrm{M} \mathrm{NaOH} \mathrm{50 \%} \mathrm{acetone} \mathrm{mixture,} \mathrm{which} \mathrm{causes} \mathrm{the}$ hydrolysis of TOFA-lignin ester bonds.

TLNP100 suspension as such without addition of cellulose fibres and APS treatment was also filtered through the filter paper but no TLNPs remained on the paper sheet.
Antimicrobial properties of TLNP functionalized cellulose surfaces

TLNP-functionalized cellulose surfaces and also allylated cellulose without any TLNPs had antimicrobial activity and bacterial cells applied on the surface died during a $30 \mathrm{~min}$ exposure (Table 3 ). During the experiment bacterial cells survived on the filter paper, unmodified cellulose and silver plaster. This indicates fast interaction of the target bacteria with allylated cellulose and functionalized cellulose surfaces. Phenolic hydroxyl and allyloxy groups of compounds have previously been linked to antimicrobial efficacy (Ultee et al. 2002; Arumugam et al. 2010). In addition, Fillat et al. (2012) have observed a similar antimicrobial activity of some natural phenols grafted on flax fibres used in handsheet products and applications.

\section{Conclusions}

In this work, we presented preparation of spherical lignin nanoparticles from TOFA-conjugated kraft lignin. The double bonds in the TOFA chain opens up a route for further functionalization. We have utilized the double bonds to covalently link the TOFAlignin nanoparticles with the fibrous cellulose material. The results show how TOFA conjugated nanoparticles were evenly distributed on allylated cellulose fibres, where the reactive double bonds from both nanoparticles and cellulose enabled more efficient covalent coupling between these materials. The reaction between TLNPs and unmodified cellulose fibres was less efficient and TLNPs were observed to react more with themselves and formed larger aggregates on the cellulose fibres.

The TLNP solutions possessed antimicrobial activity, and the activity remained after attachment onto 
cellulose. Further research needs to be done with antimicrobial mechanisms e.g. microbial cell membrane interactions of lignin nanoparticles. In addition, microbial cell interactions with the functionalized surfaces should be examined in more detail. However, current results indicate that also the reactive double bonds alone without any other antimicrobial moieties seem to play a role in antimicrobial activity.

Potential applications are, for example, bio-active and antimicrobial self-adhesive tapes, papers, handsheets, medical textiles, hygiene product etc.

Acknowledgments Open access funding provided by Technical Research Centre of Finland (VTT). We are thankful to Aalto University and VTT for financing this research through the Forest meets chemistry program and the FinnCERES program of the Finnish Academy. Riitta Suihkonen, Päivi Matikainen (DLS), Niina Torttila (microbiology), Kari Kammiovirta (TLNP preparation), and Yukho Sok-Sar (TOFA lignin preparation and NP preparation) are thanked for skilful technical assistance. This work was carried out under the Academy of Finland's Centers of Excellence Programme (2014-2019) and the FinnCERES programme (2018-2019), and made use of the Aalto University Nanomicroscopy Centre (Aalto NMC).

Open Access This article is distributed under the terms of the Creative Commons Attribution 4.0 International License (http:// creativecommons.org/licenses/by/4.0/), which permits unrestricted use, distribution, and reproduction in any medium, provided you give appropriate credit to the original author(s) and the source, provide a link to the Creative Commons license, and indicate if changes were made.

\section{References}

Alakomi HL, Paananen A, Suihko ML, Helander IM, Saarela M (2006) Weakening effect of cell permeabilizers on gramnegative bacteria causing biodeterioration. Appl Environ Microbiol 72:4695-4703

Aro T, Fatehi P (2017) Tall oil production from black liquor: challenges and opportunities. Sep Purif Technol 175:469-480

Arumugam M, Mitra A, Jaisankar P, Dasgupta S, Sen T, Gachhui R, Mukhopadhyay K, Mukherjee J (2010) Isolation of an unusual metabolite 2-allyloxypheno from a marine actinobacterium, its biological activities and applications. Appl Microbiol Biotechnol 86:109-117

Ashok RPB, Oinas P, Lintinen K, Sarwar G, Kostiainen MA, Österberg M (2018) Techno-economic assessment for the large-scale production of colloidal lignin particles. Green Chem 20:4911-4919

Crestini C, Lange H, Sette M, Argyropoulos DS (2017) On the structure of softwood kraft lignin. Green Chem 19:4104-4124
Doherty WOS, Mousavioun P, Fellows CM (2011) Value-adding to cellulosic ethanol: lignin polymers. Ind Crops Prod 33:259-276

Domínguez-Robles J, Tamminen T, Liitiä T, Peresin MS, Rodríguez A, Jääskeläinen A-S (2018) Aqueous acetone fractionation of kraft, organosolv and soda lignins. Int $\mathbf{J}$ Biol Macromol 106:9797-9987

Dong X, Dong M, Lu Y, Turley A, Jin T, Wu C (2011) Antimicrobial and antioxidant activities of lignin from residue of corn stover to ethanol production. Ind Crops Prod 34:1629-1634

Duval A, Lawoko M (2014) A review on lignin-based polymeric, micro- and nano-structured materials. React Funct Polym 85:78-96

Farooq M, Zou T, Riviere G, Sipponen MH, Österberg M (2019) Strong, ductile, and waterproof cellulose nanofibril composite films with colloidal lignin particles. Biomacromolecules 20:693-704

Figueiredo P, Lintinen K, Kiriazis A, Hynninen V, Liu Z, Ramos TB, Rahikkala A, Correia A, Kohout T, Sarmento B, YliKauhaluoma JT, Hirvonen JT, Ikkala O, Kostiainen MA, Santos HA (2017) In vitro evaluation of biodegradable lignin-based nanoparticles for drug delivery and anhanced antiproliferation effect in cancer cells. Biomaterials 121:97-108

Figueirodo P, Ferro C, Kemell M, Kiriazis A, Lintinen K, Florindo H, Yli-Kauhaluoma J, Hirvonen J, Kostiainen MA, Santos HA (2018) Properties and chemical modifications of lignin: towards lignin-based nanomaterials for biomedical applications. Prog Mater Sci 93:233-269

Fillat A, Gallardo O, Vidal T, Pastor FIJ, Díaz P, Roncero MB (2012) Enzymatic grafting of natural phenols to flax fibres: development of antimicrobial properties. Carbohydr Polym 87:146-152

Granata A, Argyropoulos D (1995) 2-Chloro-4,4,5,5-tetramethyl-1,3,2-dioxaphospholane, a reagent for the accurate determination of the uncondensed and condensed phenolic moieties in lignins. J Agric Food Chem 43:1538-1544

Hajipour MJ, Fromm KM, Ashkarran AA, de Aberasturi DJ, de Larramendi IR, Rojo T, Serpooshan V, Parak WJ, Mahmoudi M (2012) Antibacterial properties of nanoparticles. Trends Biotechnol 30:499-511

Hu S, Hsieh YL (2015) Synthesis of surface bound silver nanoparticles on cellulose fibers using lignin as multifunctional agent. Carbohydr Polym 131:134-141

Hu L, Stevanovic T, Rodrigue D (2014) Unmodified and esterified kraft lignin-filled polyethylene composites: compatibilization by free-radical grafting. J Appl Polym $132: 41484$

Hult EL, Ropponen J, Poppius-Levlin K, Ohra-Aho T, Tamminen $T$ (2013) Enhancing the barrier properties of paper board by a novel lignin coating. Ind Crops Prod 50:694-700

Klapiszewski L, Rzemieniecki T, Krawczyk M, Malina D, Norman M, Zdarta J, Majchrzak I, Dobrowolska A, Czaczyk K, Jesionowski T (2015) Kraft lignin/silica-AgNPs as a functional material with antibacterial actibity. Colloids Surf B Biointerfaces 134:220-228

Laurichesse S, Avérous L (2014) Chemical modification of lignins: towards biobased polymer. Prog Polym Sci 39:1266-1290 
Leskinen T, Witos J, Valle-Delgado JJ, Lintinen K, Kostiainen M, Wiedmer SK, Österberg M, Mattinen ML (2017) Adsorption of proteins on colloidal lignin particles for advanced biomaterials. Biomacromolecules 18:2767-2776

Li M, Zhu Z, Pan X (2011) Effects of starch acryloylation on the grafting efficiency, adhesion, and film properties of acryloylated starch-g-poly (acrylic acid) for warp sizing. Starch/Stärke 63:683-691

Li H, Pang Z, Gao P, Wang L (2015) Fe(III)-catalyzed grafting copolymerization of lignin with styrene and methyl methacrylated through AGET ATRP using triphenyl phospine as a ligand. RSC Adv 5:54387-54394

Lievonen M, Valle-Delgado JJ, Mattinen ML, Hult EL, Lintinen K, Kostiainen MA, Paananen A, Szilway GR, Setälä H, Österberg M (2016) A simple process for lignin nanoparticle preparation. Green Chem 18:1416-1422

Lindberg L (2003) Forchem starts tall oil distillation at Rauma. Paperi ja Puu-Paper and Timber 85:142

Lintinen K, Xiao Y, Ashok RB, Leskinen T, Sakarinen E, Sipponen M, Muhammad F, Oinas P, Österberg M, Kostiainen MA (2018) Closed cycle production of concentrated and dry redispersible colloidal lignin particles with a three solvent polarity exchange method. Green Chem 20:843-850

Lu FJ, Chu LH, Gau RJ (1998) Free radical-scavenging properties of lignin. Nutr Cancer 30:31-38

Luo S, Cao J, McDonald AG (2018) Cross-linkin of technical lignin via esterification and thermally initiated free radical reaction. Ind Crops Prod 121:169-179

Pawar SN, Venditti RA, Jameel H, Chang HM, Ayoub A (2016) Engineering physical and chemical properties of softwood kraft lignin by fatty acid substitution. Ind Crops Prod 89:128-134

Pohjanlehto H, Setälä H, Kammiovirta K, Harlin A (2011) The use of $\mathrm{N}, \mathrm{N}^{\prime}$-diallylaldardiamides as cross-linkers in xylan derivatives-based hydrogels. Carbohydr Polym 346:2736-2745

Qi H, Liebert T, Heinze T (2012) Homogeneous synthesis of 3-allyloxy-2-hydroxypropyl-cellulose in $\mathrm{NaOH} / \mathrm{urea}$ aqueous system. Cellulose 19:925-932

Ralph J, Lundquist K, Brunow G, Lu F, Kim H, Schatz PF, Marita JM, Hatfield RD, Ralph SA, Christensen JH, Boerjan W (2004) Lignins: natural polymers from oxidative coupling of 4-hydroxyphenyl propanoids. Phytochem Rev 3:29-60

Rämänen P, Maunu SL (2014) Structure of tall oil fatty acidbased alkyd resins and alkyd-acrylic copolymers studied by NMR spectroscopy. Prog Org Coat 77:361-368

Romero-Urbina DG, Lara HH, Velázquez-Salazar J, ArellanoJiménez J, Larios E, Srinivasan A, Lopez-Ribot JL, Yacamán MJ (2015) Ultrastructural changes in methicillinresistant Staphylococcus aureus induced by positively charged silver nanoparticles. Beilstein $\mathrm{J}$ Naotechnol 6:2396-2405

Silmore KS, Gupta C, Washburn NR (2016) Tunable pickering emulstions with polymer-grafted lignin nanoparticles (PGLNs). J Colloid Interface Sci 466:91-100

Spiridon J (2018) Biological and pharmaceutical applications of lignin and its derivatives: a mini-review. Cellulose 52:543-550

Tagami A, Gioia C, Lauberts M, Budnyak T, Moriana R, Lindström ME, Sevastyanova O (2019) The grafting selectivity, solvent fractionation of softwood and hardwood kraft lignins for more efficient uses: compositional, structural, thermal, antioxidant and adsorption properties. Ind Crops Prod 129:123-134

Ultee A, Bennik MHJ, Moezelaar R (2002) The phenolic hydroxyl group of carvacrol is essential for action against the food-borne pathogen Bacillus cereus. Appl Environ Microbiol 68:1561-1568

Uschanov P, Heiskanen N, Mononen P, Maunu SL, Koskimies S (2008) Synthesis and characterization of tall oil fatty acidsbased alkyd resins and alkyd-acrylate copolymers. Prog Org Coat 63:92-99

Vehviläinen M, Kamppuri T, Setälä $H$, Grönqvist S, Rissanen M, Honkanen H, Nousiainen P (2015) Regeneration of fibres from alkaline solution containing enzyme-treated 3-allyloxy-2-hydroxypropyl substituted cellulose. Cellulose 22:2271-2282

Wang Q, Pellegrene B, Soucek MD (2018) Investigation of methyl methacrylated grafting on model single fatty acid alkyds. Ind Eng Chem Res 57:12018-12028

Yang W, Rallini M, Wang DY, Gao D, Dominici F, Torre L, Kenny JM, Puglia D (2018) Role of lignin nanoparticles in UV resistance, thermal and mechanical performance of PMMA nanocomposites prepared by a combined freeradical graft polymerization/masterbatch procedure. Composite Part A 107:61-69

Yearla SR, Padmasree K (2016) Preparation and characterization of lignin nanoparticles: evaluation of their potential as antioxidants and UV protectants. J Exp Nanosci 11:289-302

Zhao W, Simmons B, Singh S, Ragauskas A, Cheng G (2016) From lignin association to nano-/micro-particle preparation: extracting higher value of lignin. Green Chem 18:5693-5700

Zhu Z, Li M, Jin E (2009) Effect of an allyl pretreatment of starch on the grafting efficiency and properties of allyl starch-g-poly (acrylic acid). J Appl Polym Sci 112:2822-2829

Publisher's Note Springer Nature remains neutral with regard to jurisdictional claims in published maps and institutional affiliations. 